\title{
Benefits of Managed Grazing: A Manager's Perspective
}

\section{By Bob Budd and Jim Thorpe}

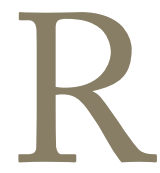

ecent discussions of the merits and scientific bases for the comparative benefits of rotational grazing systems have been clouded by a lack of agreement on definitions and by actuality that the experimental results are not expressed in terms that address desired outcomes of many managers, particularly habitat values for wildlife. "Grazing" as an ecological process has been addressed in more than a dozen professional journals of disciplines such as fisheries, wildlife, range science, ecology, conservation biology, forestry, applied ecology, limnology, and others. Some of that body of literature reflects basic relationships between management and ecological processes-such as stocking rates, duration of grazing, season of use, type of forage, species or class of grazer-but many lack relevance to a variety of different management strategies on the ground.

The most common criticism of grazing experiments has been centered on their lack of relevance to the time and space in which managers practice. Small plot experiments are not particularly well suited to investigating or predicting landscape-scale processes, and large-scale experiments are expensive. While it may be "possible" to interpret historic and prehistoric interactions between living organisms at scale, the cost is prohibitive. It is virtually impossible to compare and contrast grazing management methods at spatial or temporal scales, between and among different ecosystems, and especially between different managers. In their recent synthesis paper, Briske et al. ${ }^{1}$ raised the issue of the importance of management based on their analysis of literature comparing continuous grazing with rotational grazing systems, and a debate has ensued.

In repeated criticisms of Briske et al. we have found neither an indictment of rotational grazing nor a validation of continuous (season-long) grazing, yet both have been the conclusion of some critical readers. Inasmuch as Briske et al.'s conclusion holds that rotational grazing is not a panacea, few can disagree. However, the alternative interpretation of the same set of experimental results to conclude that rotational grazing is detrimental to a variety of resource attributes is equally invalid.

A wide array of the world's ecosystems evolved with variable levels of grazing, fire, and often the combination of the two, leading to patterns that proponents of both rotational grazing systems and continuous grazing have used as models for design and implementation. Much of the basis for planning and assessing grazing management historically has been based in the demonstrated range of species responses to defoliation. At the community scale, areas burned in one year are grazed selectively in the next, allowing fuel to build in other areas. Historically, many of these fires were individually small but were large in landscape scale, and recent use of "patch burning" to create diversity and wildlife habitat is a means of mimicking natural process. These "chocolate chips" in the cookie are highly valuable in restoring native species like prairie-chickens and quails. Over time, the impacts of grazing were also moved across the landscape in a manner that created a combination of plants, patches, and habitat types occupied by a diversity of wildlife. At the landscape scale, unique areas such as springs and streams might attract higher levels of herbivory across seasons, creating unique habitats for species like the mountain plover (Charadrius montanus) or burrowing owl (Athene cunicularia). Conversely, areas inaccessible or unattractive to grazers might have little use at all, creating dense nesting cover or winter forage for deer and elk. Domestic sheep operators have long understood the value of windswept ridges and arid areas where water is limiting in summer but where snow and shrubs are a valuable forage combination in winter. And a variety of wildlife species typically range in and out of seasonal habitats that may appear to be of little value in one season or another.

In addition to grazing and fire, other ecological processes must be considered when developing management alternatives. Drought is a common occurrence, as is seasonal flooding. Management that recognizes the limiting nature of drought may allow market options as well, such as combinations of cow-calf and stocker programs, though persistent drought will challenge the abilities of the best managers. ${ }^{2}$ Erosion in many areas is an ongoing and unavoidable natural process, which, when brought into the management equation, may actually accelerate recovery of riparian species such as cottonwood (Populus deltoides), birch (Betula spp.), and willow (Salix spp.). In a shorter time scale, keystone species, especially beaver (Castor spp.), can have strong 
influences on ecosystem response. The mode of vegetation reproduction and regeneration is another process that should be considered in the design of grazing. Cool- and warmseason grasses will respond to management differently, as will bunchgrasses and rhizomatous species. Using seasonal rotation may also help to maintain diversity (species evenness) within the plant community, and in some cases, may be essential to recovery of species that have been preferentially grazed. Understanding the processes that shape plant communities is critical background in designing grazing systems that are both resilient and productive for livestock and wildlife.

As with any management process, the success of all grazing management should be predicated and evaluated on a desired outcome - that is, a result. Without an outcomebased approach, evaluation of management is impossible. However, objectives focused solely on ecological or economic indicators are equally incomplete. In cases where grazing management is oriented primarily toward livestock production, as in irrigated pastures, production goals may be largely one-dimensional in an economic sense, but even these should not ignore ecological and environmental considerations, such as water quality, soil health, plant diversity, and habitat. Conversely, on public lands, production goals may be effectively trumped by other values, such as nesting cover for sage-grouse (Centrocercus urophasianus; residual forage), nesting habitat for mountain plovers (bare ground), crucial winter range for mule deer (shrub communities), or riparian and wetland health. In those settings, the focus may be primarily on ecological outcomes, but those outcomes must also recognize economic constraints.

The implementation of most grazing systems can be traced as a response to a handful of stimuli. Overstocking became synonymous with continuous grazing because that was the primary method of use at the time. Early range management textbooks correctly identified the cardinal principles of grazing management as stocking rate, distribution, season of use, and kind and class of animal., Rest or deferment was incorporated into grazing as a means to achieve specific management goals (usually plant related), and it took little time for that notion to translate into restand-rotation methods. While these rotational approaches were often a response to severe range degradation, results led many other managers to consider the tactic for a variety of reasons. In many ways, this was the genesis of the rangeland profession, an attempt to restore and understand ecological systems - many long ignored and some abused. With greater understanding of plant physiology and plantanimal interactions, "rest" was expanded to include the concept of deferment, and ultimately, recovery periods from bouts of grazing. Most recently, advances in human understanding of animal behavior have led to development of fairly intricate grazing management systems, many of which use grazing animals to control invasive plants, to maintain or establish wildlife habitat, to manage natural and prescribed fire, or for other purposes.

By viewing herbivory (grazing) as a tool to achieve a desired, clearly enunciated result, managed grazing can be used to achieve multiple purposes. While continuous grazing under appropriate stocking rates and proper distribution is really "managed" grazing, rotational grazing may offer a wider range of options to managers, both for plant and animal objectives. Rotational grazing may include opportunities to employ the following to achieve economic goals: 1 ) temporary higher stock density, 2) deferment or rest, 3) spatial and temporal control, 4) seasonal use variation, and 5) livestock management.

Increased stock density may be important to attain a variety of results. Livestock have been used to eliminate weeds and to harvest less desirable species, a practice that generally requires short durations of intensive grazing followed by long periods of rest. This has led to a new field of practice, often referred to as "targeted grazing," which becomes management at an even finer scale..$^{5}$ Targeted grazing may be used to create disturbance or to solve other problems, such as the reduction of fuel in fire-prone locales. Ecological objectives, such as the variability of habitat types required by species like sage-grouse, bobwhite quail, or mountain plover, are often achieved by using varying stock density to maintain or create a heterogeneous vegetation pattern at the landscape scale, although concentrating animals can homogenize plant species and communities. Different numbers of animals may also lead to subtle behavioral changes that may create different management options. ${ }^{6}$

Deferment or rest may be necessary to allow for prescribed or natural fire. In areas where fire is a high-risk endeavor, rotational grazing may be used to simultaneously provide fine fuels, and to reduce fuels (and fire risk) in adjacent pastures. Seasonal deferment of plant use may also contribute to the long-term health and vigor of plants, as well as seed production in areas where that form of reproduction is important. Another form of "deferment" that has shown a high level of ecological benefits in some areas is removal of livestock from riparian areas in the hot summer, following use in late spring. This pattern of use attempts to mimic historic regional patterns by herds of large ungulates that would follow a maturing forage base from basins to mountains. Historically, in the northern portions of the United States, as upland cool-season grasses began to grow, animals would switch their dietary preference, allowing woody species, like willow, to escape defoliation and to eventually flourish in lowlands. When rest or deferment is rotated seasonally among pastures over a course of years, it may be possible to increase diversity (both species composition and structure) of vegetation.

In most western rangelands, especially in some of the more marginal landscapes that include vast expanses of public lands, distribution is difficult, if not impossible, to 
manage properly using stocking rate alone. In the 1980s, concern over the condition of riparian areas on public lands became so elevated that numerous reports were issued at the federal level, the most damning a report from the (then) General Accounting Office. ${ }^{7}$ Management that controls season of use and duration of grazing directly impacts riparian area recovery and maintenance, often without restricting access to water or vegetation in arid ecosystems. On smaller operations, or in more mesic environments, rotational grazing may allow managers to better utilize seasonal plant species; this strategy has been valuable in restoring tallgrass prairie species in fragmented agricultural landscapes, while controlling introduced species, such as fescue. Many operators in Missouri have found that grazing non-native species in a very aggressive grazing regime allows them the ability to restore native prairie species that are highly productive and resilient.

Rotational grazing may be essential to achieve some economic goals. Every operation is unique, and each will have a different set of parameters that must be met to be successful economically. The ability to concentrate females during the breeding season, to disperse animals during parturition, to manage multiple herds, to take advantage of specific vegetation types (or eliminate undesirable plants), to prepare for prescribed fire (or recover from wildfire), or to address other economic issues may be the most important reasons for some managers to employ a managed grazing strategy. When a strong management system is in place at a reasonable stocking rate, operations may become more resilient to drought and other variables. And, in some economic environments, light stocking simply may not be viable for a variety of reasons. On public lands and on rangelands where elevation, seasonal variation, poisonous plants, or other factors limit use, those limitations may manifest biologically. In other cases, the economic limitations of management may lead to higher stock densities and lower durations of grazing. Every situation is unique and should be evaluated in light of the realities of that particular operation.

Rotational grazing "systems" will not work without a high level of management and monitoring. This may be the most valid criticism leveled at rotational grazing. If a management system is not clearly outlined and understood, or if it is not evaluated regularly, the system is likely to fail to deliver the desired objectives. However, the same can be said for continuous grazing. The process of continuous development of grazing strategies, coupled with honest feedback from monitoring, affords managers a clearer picture of both ecological and economic outcomes. In most situations, managers will find that a combination of management alternatives may be the most beneficial.

So, what are all these alternatives? In general, there are four strategies: 1) continuous, 2) rest-rotation, 3) deferred, and 4) intensive (or twice-over). Keys to success under continuous grazing are correct stocking rates, adequate water, and a reasonably uniform vegetation type, or the use of distribution tools. Rest-rotation systems incorporate rest in some pasture(s) annually, and they usually employ seasonal rotation of pastures. By doing so, these systems will also defer pastures used late in the season. A deferral system does not rest pastures but rotates seasonal use. More intensive systems, including those pioneered under the Holistic Resource Management and other grazing planning guidelines, may use pastures more than once each growing season. Providing plants an adequate recovery period after grazing is essential to this form of management.

It is not uncommon to have multiple strategies employed on a single ranch. One manager has used continuous grazing at appropriate stocking on an upland pasture to manage his purebred cow herd. Commercial cows were managed in a rest-rotation system on public and private lands, and stocker cattle were intensively grazed on irrigated meadows. This allows the manager to match his ecological systems to a diverse mix of agricultural products, thus controlling market risk to some degree.

The recent "debate" over the use of rotational grazing systems seems somewhat misguided, in part because terms like "rotational," "planned," "pulsed," or "managed" grazing are not recipes, but general concepts that must be adapted to each unique situation. It is possible to rotate or manage grazing with any stocking rate or density. It is equally possible to manage grazing to achieve any level of utilization, and rotation can take place within seasons or across seasons. Clearly, light to moderate grazing has been shown to maintain or even slightly increase vegetative production in a variety of ecosystems. Many of those studies seem to support the "take half-leave half" mantra of grassland conservation, but that approach may not address issues of biodiversity at a landscape scale or take into account the responses to defoliation of important species (i.e. black grama [Bouteloua eriopoda] in desert grasslands).

The "art" of range management lies in understanding the natural and economic systems in which grazing is a fundamental process and in applying the appropriate tools to achieve explicit goals or objectives. Much of the attraction to rotational grazing systems comes from historic observations and perceptions of herbivore behavior in extensive unfragmented landscapes, where constant motion and different utilization patterns created and maintained highly variable, biologically rich ecosystems. It is interesting to note that many of the animal species of greatest concern actually choose areas that are heavily disturbed, while other species in the same ecosystem will seek out the most undisturbed habitats. For instance, keystone species like prairie dogs (Cynomys spp.) may thrive in and contribute to the disturbance of heavily grazed uplands, while beavers both remove and increase vegetation along the streams.

Before choosing a management scheme, it is imperative that managers undergo a thorough evaluation of these 
elements: 1) historic patterns of natural processes, including the nature and condition of the resource base; 2) skills, availability, and experience of management; and 3) the economic and ecological objectives and constraints of a grazing operation. In addition, a clearly defined system for evaluation with clear links to management actions is necessary in order to respond to unexpected events. Like the management of any complex system, a clear understanding of the ecology, coupled with measurable, articulated goals is essential to success.

In light of the controversy, and especially in view of the tremendous dialogue created by Briske et al., ${ }^{1}$ we encourage the investigation of these management choices to move forward. While it is true that there has been little empirical research of grazing systems at commercial scales, there is an abundance of data from federal land management agencies, private landowners, and consultants that could be the basis for comprehensive review of the response of rangelands to different management schemes. Some of these data sets go back more than 60 years and would be an excellent point of departure. Given the level of monitoring and analysis on rangelands in the past 40 years, this type of data could be further subdivided by region, vegetative type, soils, or other components. And analysis of the data should include the input of managers as well as researchers. Such an effort would do a great deal to alleviate much of the misunderstanding and miscommunication that appears to be present on either side of the "debate" and would lead to positive reconciliation of the art and science of rangeland management.

\section{References}

1. Briske, D. D., J. D. Derner, J. R. Brown, S. D. Fuhlendorf, W. R. Teague, K. M. Havstad, R. L. Gillen, A. J. Ash, and W. D. Willms. 2008. Rotational grazing on rangelands: reconciliation of perception and experimental evidence. Rangeland Ecology and Management 61:3-17.

2. Thurow, T. L., and C. A. Taylor, JR. 1999. Viewpoint: the role of drought in range management. Journal of Range Management 52:413-419.

3. Sampson, A. W. 1923. Range and pasture management. New York, NY, USA: John Wiley. 421 p.

4. Stoddard, L. A., and A. D. Smith. 1943. Range management. New York, NY, USA: McGraw-Hill. 547 p.

5. Launchbaugh, K., and J. W. Walker. 2006. Targeted grazing: a new paradigm for livestock Management. In: K. Launchbaugh [ED.]. Targeted grazing: a natural approach to vegetation management and landscape enhancement. American Sheep Industry Association. Available at: http://www.cnr.uidaho. edu/rx-grazing/handbook/Chapter_1_Targeted_Grazing.pdf. Accessed 2 October 2009.

6. Provenza, F. D. 2003. Foraging behavior: managing to survive in a world of change. Utah State University. Available at: http:// www.behave.net/index.html. Accessed 2 October 2009.

7. General Accounting Office. 1988. Public rangelands: some riparian areas restored but widespread improvement will be slow. GAO/RCED-88-105. Gaithersburg, MD, USA: General Accounting Office. 86 p.

Authors are Executive Director, Wyoming Wildlife and Natural Resource Trust, Riverton, WY 82501, USA, bbudd@state.wy.us (Budd); and Rancher, Newkirk, NM 88431, USA (Thorpe).

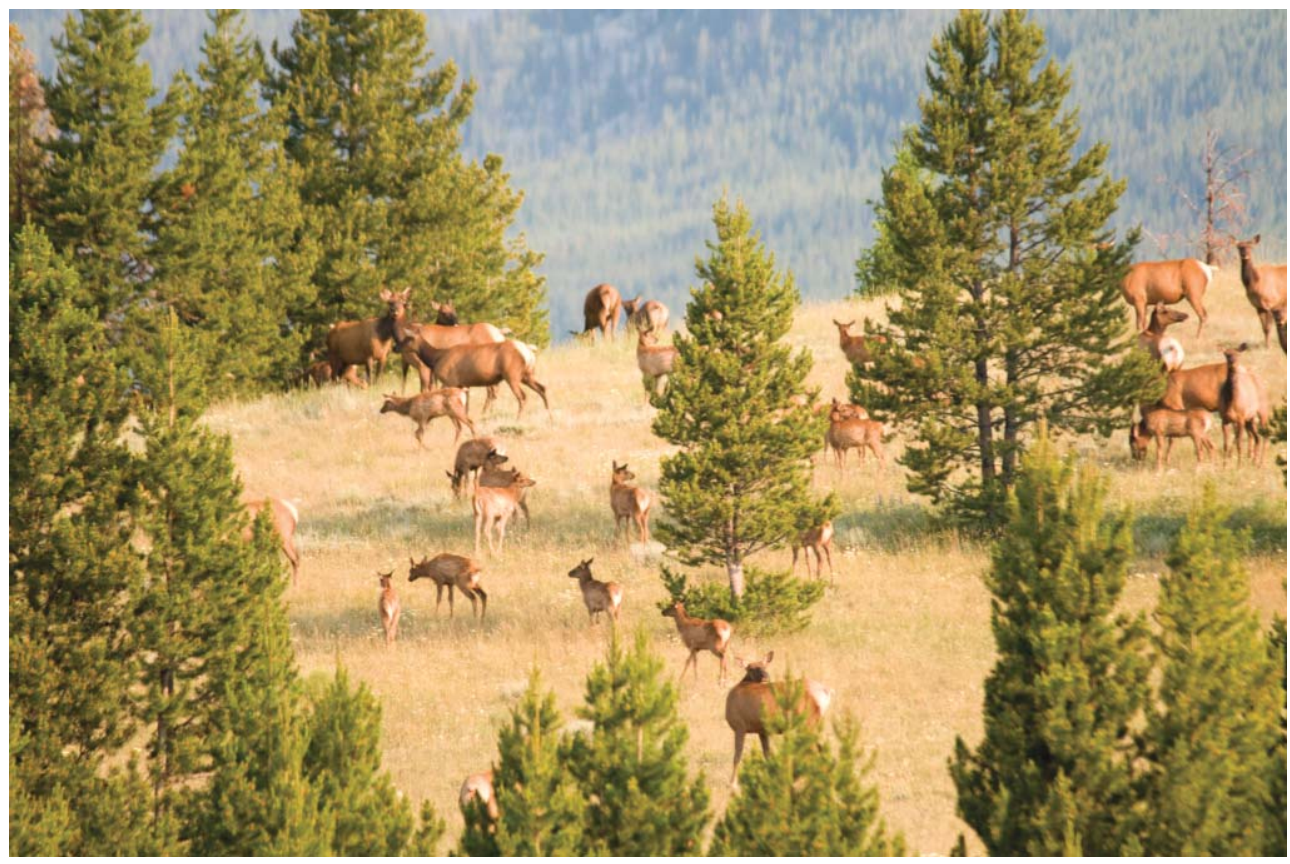

Elk cows and calves grazing following livestock in a rotational grazing system on the Mt. Haggin Wildlife Management Area. Photo courtesy of Mike Frasina. 